\title{
Identification of the growth hormone receptor in an advanced teleost, the tilapia (Oreochromis mossambicus) with special reference to its distinct expression pattern in the ovary
}

\author{
S Kajimura, N Kawaguchi, T Kaneko, I Kawazoe, T Hirano"', \\ N Visitacion ${ }^{1}$, E G Grau ${ }^{1}$ and K Aida \\ Department of Aquatic Bioscience, Graduate School of Agricultural and Life Sciences, University of Tokyo, 1-1-1 Yayoi, Bunkyo, Tokyo, 113-8657, Japan \\ ${ }^{1}$ Hawaii Institute of Marine Biology, University of Hawaii, P.O. Box 1346, Kaneohe, Hawaii 96744, USA \\ (Requests for offprints should be addressed to T Kaneko; Email: kaneko@marine.fs.a.u-tokyo.ac.jp)
}

\begin{abstract}
There is considerable evidence that the GH/IGF-I axis plays an important role in female reproduction. We report the isolation and characterization of the $\mathrm{GH}$ receptor (GH-R) and its gene expression profile during oogenesis in the tilapia, Oreochromis mossambicus. cDNA encoding GH-R was cloned and sequenced from the tilapia liver. The predicted GH-R preprotein consisted of 635 amino acids and contained a putative signal peptide, an extracellular region with a characteristic motif, a single transmembrane region, and a cytoplasmic region with conserved box 1 and 2 domains. The tilapia GH-R shared 34-74\% identities with known GH-Rs in vertebrates. A binding assay using COS-7 cells showed that the cloned GH-R bound specifically to tilapia GH. Northern blot analysis showed a single mRNA transcript in the liver and ovary. In situ hybridization revealed intense signals of GH-R in
\end{abstract}

the cytoplasm and nucleus of immature oocytes. The granulosa and theca cells surrounding vitellogenic oocytes also contained the GH-R mRNA signals. About a tenfold greater level of GH-R mRNA was found in the immature oocytes versus the mature oocytes, along with high levels of IGF-I mRNA. There were no significant changes in mRNA levels of GH-R and IGF-I in the liver or in plasma IGF-I levels during oocyte development. No correlation was found between hepatic GH-R mRNA and ovarian GH-R mRNA. These results suggest that the GH/IGF-I axis in the ovary may be involved in the early phases of oogenesis, under a different regulatory mechanism of GH-R gene expression from that of the liver.

Journal of Endocrinology (2004) 181, 65-76

\section{Introduction}

The interaction between somatic growth and reproduction has been implicated in vertebrates in general. Although follicle-stimulating hormone and luteinizing hormone are the major regulators of gonadal development, there is considerable evidence that the growth hormone $(\mathrm{GH})$ / insulin-like growth factor-I (IGF-I) axis plays an important role in female reproduction, in addition to its metabolic actions for somatic growth (Hull \& Harvey 2001). In mammals, GH deficiency caused a delayed onset of puberty, which was restored by exogenous GH treatment (Ramaley \& Phares 1980, Advis et al. 1981). Coadministration of $\mathrm{GH}$ with gonadotropin $(\mathrm{GTH})$ has also been used to induce ovulation in patients who show poor sensitivity to GTH (Homburg 1996). Furthermore, Laron syndrome, $\mathrm{GH}$ insensitivity resulting from a variety of $\mathrm{GH}$ receptor $(\mathrm{GH}-\mathrm{R})$ mutations, shows a hereditary dwarfism, truncal obesity, and delayed puberty, which are restored by IGF-I treatment (Laron \& Klinger 1998).
In vitro studies in mammals have shown that $\mathrm{GH}$ enhances follicular growth and differentiation of granulosa cells (Jia et al. 1986, Yoshimura et al. 1994), steroidogenesis (Mason et al. 1990), and inhibits follicle apoptosis (Danilovich et al. 2000). In teleosts, GH potentiates the actions of GTH on ovarian steroidogenesis in the goldfish (Van der Kraak et al. 1990) and directly stimulates steroidogenesis in isolated ovarian follicles of killifish and seatrout (Singh et al. 1988, Singh \& Thomas 1993). These studies led to attempts to localize the GH-R transcripts or peptides, but the results are still ambiguous, even in mammals. GH-R is localized in a variety of rat ovarian cells including follicles (Lobie et al. 1990), granulosa cells, corpus luteum, and germinal epithelium (Carlsson et al. 1993), and also in human granulosa cells of dominant and antral follicles, and corpus luteum (Sharara \& Nieman 1994). According to Kölle et al. (1998), GH-R transcripts are co-localized with GH-R protein in the bovine oocytes of the primordial and primary follicles, in the cells of the cumulus oophorus, large granulosa lutein cells, germinal 
epithelium, and endothelial cells of ovarian vessels. In teleosts, there seems to be no report on specific localization of GH-R in the ovary, except for a report on specific binding sites for $\mathrm{GH}$ in the ovary of rainbow trout by radioreceptor assay (Gomez et al. 1999). On the other hand, localization of IGF-I and IGF-I receptor were reported in the ovarian follicle of tilapia and seabream, suggesting that fish also have an IGF-I system within the ovary (Reinecke et al. 1997, Perrot et al. 2000). Recently, GH-R cDNA has been isolated in several teleost species (Calduch-Giner et al. 2001, Lee et al. 2001, Tse et al. 2003). However, the mode of actions of GH/IGF-I in ovarian development in the fish remains unknown.

While most of our knowledge regarding hormonal regulation of the ovarian function has been derived from work on a limited number of model systems, fish offer an alternative and excellent model to clarify the functional significance of $\mathrm{GH}$ in ovarian development. Among more than 22000 species of teleosts, the tilapia (Oreochromis mossambicus) is one of the most advanced species, and shows asynchronous development of the ovary, where different developmental stages of oocytes are simultaneously present, different from salmonid species which show synchronous ovarian development, thus providing a unique model (Smith \& Haley 1988). The aim of the present study was to examine a possible role of the GH/IGF-I axis in the ovarian development of the tilapia. We have isolated and characterized GH-R cDNA, identified the localization of the GH-R transcripts in the ovary, and examined the gene expression profiles of GH-R and IGF-I during ovarian development.

\section{Materials and Methods}

\section{Samples}

Female tilapia (Oreochromis mossambicus), weighing 40$80 \mathrm{~g}$, were reared in circular 700 liter tanks in fresh water under natural condition at the Hawaii Institute of Marine Biology, University of Hawaii, Manoa. Water temperature was maintained at $25 \pm 2{ }^{\circ} \mathrm{C}$. They were fed twice daily with ProForm (Agro Pacific, Chilliwaeck, BC, Canada), approximately $2 \%$ of body weight per day. The experiments were conducted in accordance with the principles and procedures approved by the Institutional Animal Care and Use Committee, University of Hawaii. For gene expression studies, female tilapia, weighing 40-180 g, were sampled at the Ocean Research Institute, University of Tokyo.

\section{cDNA cloning of tilapia $G H-R$}

Total RNA was extracted from the tilapia liver using an RNA extraction solution (ISOGEN; Nippon Gene, To- kyo, Japan), and poly(A) ${ }^{+}$RNA was subsequently purified from total RNA with Oligotex-dT 30 (Takara, Shiga, Japan). Double-strand cDNA was reverse transcribed using a Marathon cDNA Amplification Kit (CLONTECH Laboratories, Palo Alto, CA, USA) according to the manufacturer's instruction. Degenerate primers, F1 (5'-GAY CCI CCM RTD KSI CTI AAC TGG AC-3'), R1 (5'-TYG CTI ACY TGI GYA TAR AAG TC-3'), and R2 (5'-AGC TSD ATG AAC TCN ACC CA-3'), were designed based on the known cDNA sequences of vertebrate $\mathrm{GH}-\mathrm{R}$. PCR was performed in a thermal cycler PC-701 (Astec, Fukuoka, Japan) in $20 \mu$ l containing $1 \times$ PCR buffer (Takara), $200 \mu \mathrm{M}$ dNTPs (Takara), $0.5 \mathrm{U}$ Taq DNA polymerase (Takara), $0.5 \mu \mathrm{M}$ of a primer pair (F1 and R1), and an appropriate amount of the cDNA template. The PCR was performed as follows: $94{ }^{\circ} \mathrm{C}$ for $2 \mathrm{~min}, 40$ cycles at $94{ }^{\circ} \mathrm{C}$ for $1 \mathrm{~min}, 50^{\circ} \mathrm{C}$ for $1 \mathrm{~min}$, $72{ }^{\circ} \mathrm{C}$ for $1 \mathrm{~min}$, and $72{ }^{\circ} \mathrm{C}$ for $7 \mathrm{~min}$. Diluted PCR product was used for the nested PCR with F1 and R2 under the same conditions as the first PCR. The PCR products were analyzed on a $2 \cdot 0 \%$ agarose gel and ligated into pBluescript II SK $(-)$ vector (Stratagene, La Jolla, CA, USA). Purified plasmids were sequenced using a DNA sequencer ABI PRISM 310 (Applied Biosystems, Foster City, CA, USA).

After determination of the partial cDNA sequences, rapid amplification of cDNA ends (RACE) was employed. For 3'-RACE, specific primers, F2 (5'-GCT ATT GAA GAA GGG GAA GCT GGA TGA GC-3') and F3 (5'-TAT GCT GAG TGG TGG AGG AAT GGA TGG C-3'), were designed. For 5'-RACE, R3 (5'-AGA CTG TCG CTG AAT GTC CAA TGC TTC C-3') and R4 $\left(5^{\prime}\right.$-CTC ATA CTC CAC ACG CAT CCA TCC CAA CC-3') were also designed and used for primary and nested PCR respectively. PCR was carried out with a specific primer and an adaptor primer under the conditions of $94{ }^{\circ} \mathrm{C}$ for 2 min, 5 cycles at $94{ }^{\circ} \mathrm{C}$ for $30 \mathrm{~s}$ and $72{ }^{\circ} \mathrm{C}$ for $2 \mathrm{~min}, 5$ cycles at $94{ }^{\circ} \mathrm{C}$ for $30 \mathrm{~s}$ and $70{ }^{\circ} \mathrm{C}$ for $2 \mathrm{~min}, 30$ cycles at $94{ }^{\circ} \mathrm{C}$ for $30 \mathrm{~s}$ and $68^{\circ} \mathrm{C}$ for $2 \mathrm{~min}$, and $72{ }^{\circ} \mathrm{C}$ for $7 \mathrm{~min}$. PCR products were subcloned and sequenced as described above. Sequence data were analyzed by Sequencher software version 3·1·1 (Hitachi, Tokyo, Japan) and SeqEd software version 1.0.3 (Perkin-Elmer, Branchburg, NJ, USA). The nucleotide sequence was determined by analyzing more than six clones from distinct amplifications and reverse transcriptions to avoid errors. Amino acid sequence alignment was performed using the CLUSTAL W multiple sequences alignment program (Thompson et al. 1994).

\section{Functional analysis of tilapia $G H-R$}

A cDNA fragment including the open reading frame of GH-R was synthesized with a forward primer $\left(5^{\prime}-\mathrm{CTT}\right.$ CTC GAG GCC ACC ATG GCT CTC TCG CCC TCC $\left.T-3^{\prime}\right)$ and a reverse primer $\left(5^{\prime}\right.$-GAT CTC GAG 
GTC ATT TCA TTG TGA GAG GTT CCC-3'), and subcloned into the expression verctor pcDNA3 (Invitrogen, Carlsbad, CA, USA). The vector with or without GH-R cDNA was transfected into monolayer cultures of COS-7 cells using TransFast transfection reagent (Promega Corp., Madison, WI, USA). COS-7 cells were cultured in Dulbecco's modified Eagle's medium containing $10 \%$ fetal bovine serum in $5 \% \mathrm{CO}_{2} / 95 \%$ air at $37{ }^{\circ} \mathrm{C}$ for $48 \mathrm{~h}$.

Tilapia GH $(5 \mu \mathrm{g})$ was iodinated by chloramine-T, and used for binding assays as a ligand. After the medium was aspirated, confluent cells in six-well plates were washed in phosphate-buffered saline (PBS) containing $0.5 \%$ bovine serum albumin (BSA; Sigma, St Louis, MO, USA). The binding assays were conducted by adding $1 \mathrm{ml}$ iodinated GH (approximately 20000 c.p.m.) to each well with or without non-radioactive GH $(1 \mu \mathrm{g})$, following Zhang et al. (2000) with modifications. After incubation for $18 \mathrm{~h}$ at $4{ }^{\circ} \mathrm{C}$, the medium was aspirated and the cells were washed in PBS containing BSA, and solubilized in $0.1 \mathrm{M} \mathrm{NaOH}$ with $1 \%$ SDS. The radioactivities in the solubilized cells were counted in a gamma counter.

For the competitive binding assay, approximately $1 \times 10^{6}$ cells in $300 \mu \mathrm{l}$ binding assay buffer $(40 \mathrm{mM}$ Tris- $\mathrm{HCl}, 10 \mathrm{mM} \mathrm{CaCl}_{2}$, and $\left.0 \cdot 1 \% \mathrm{BSA}, \mathrm{pH} 7 \cdot 4\right)$ were incubated with $100 \mu \mathrm{l}$ iodinated GH (20 000-25000 c.p.m.) and $100 \mu \mathrm{l}$ serial dilutions $(0 \cdot 015-1000 \mathrm{ng})$ of non-radioactive tilapia $\mathrm{GH}$ or tilapia prolactins $\left(\mathrm{PRL}_{188}\right.$ and $\left.\mathrm{PRL}_{177}\right)$. After incubating overnight at $4{ }^{\circ} \mathrm{C}, 2 \mathrm{ml}$ ice-cold assay buffer were added to the each tube, and centrifuged at $750 \mathrm{~g}$ for $10 \mathrm{~min}$. Subsequently, the tubes were aspirated and then counted in a gamma counter. Non-specific binding were quantified in the presence of $1 \mu \mathrm{g}$ non-radioactive GH. Assays were conducted in triplicate and repeated at least twice by distinct transfection. Data were analyzed using PRIZM software (GraphPad Software, San Diego, CA, USA).

\section{Tissue distribution analysis of $G H-R$}

Total RNA was extracted from brain, pituitary, gill, liver, spleen, head kidney, body kidney, heart, skeletal muscle, stomach, intestine, ovary, and testis as described above. After treatment with DNase (Invitrogen), the total RNA $(2.5 \mu \mathrm{g})$ was reverse transcribed with random hexamer primers and SuperScript II reverse transcriptase following the manufacturer's protocol (Invitrogen). RT-PCR was performed with a primer pair (5'-CTG CAG CCA CAA CGG A-3')/(5'-CTT TCC TGG TGA ATC AGC C-3') under the PCR cycles at $94{ }^{\circ} \mathrm{C}$ for 2 min, 32 cycles at $94{ }^{\circ} \mathrm{C}$ for $1 \mathrm{~min}, 55^{\circ} \mathrm{C}$ for $1 \mathrm{~min}$, and $72{ }^{\circ} \mathrm{C}$ for $1 \mathrm{~min}$. PCR products were analyzed on a $2 \cdot 0 \%$ agarose gel and stained with ethidium bromide. A plasmid containing the full length of GH-R cDNA was used as a positive control, and distilled water as a negative control.

\section{Northern blot analysis}

A cDNA including the full open frame region of tilapia GH-R was used as a probe. The cDNA was labeled using a random primed DNA labeling kit (Takara) with $\left[\alpha-{ }^{32} \mathrm{P}\right] \mathrm{dCTP}$ (Amersham Bioscience, Piscataway, NJ, USA). The specific activities were greater than $1 \times 10^{9}$ c.p.m. $/ \mu$ g. Four micrograms of poly $(\mathrm{A})^{+}$RNA purified from the liver and ovary were fractionated on a $1 \cdot 1 \%$ formaldehyde agarose gel and transferred to a Hybond $\mathrm{N}^{+}$ nylon membrane (Amersham Bioscience). After prehybridization in hybridization buffer (PerfecHyb; Toyobo, Tokyo, Japan), the membrane was hybridized with DNA probe at $65^{\circ} \mathrm{C}$ for $18 \mathrm{~h}$. The membranes were then washed for $10 \mathrm{~min}$ in $2 \times \mathrm{SSC}$ with $1 \% \mathrm{SDS}$ at $65^{\circ} \mathrm{C}$, followed by a $10-$ min wash in $0 \cdot 2 \times$ SSC with $0 \cdot 1 \%$ SDS at $65{ }^{\circ} \mathrm{C}$. The membrane was exposed to Fuji X-ray film (Fuji Film, Tokyo, Japan) at $-80^{\circ} \mathrm{C}$ for 1 day.

\section{In situ hybridization}

Tilapia ovaries (gonadosomatic index (GSI); gonad weight/body weight $\times 100: 0 \cdot 62-4 \cdot 50 \%)$ were embedded in paraplast and cut at $6 \mu \mathrm{m}$. Subsequently, sections were deparaffinized by washing in xylene and series of ethanol. An antisense oligonucleotide probe (5'-GTT AAG GAG CAG ACT GTG ATG GCT GTC TAA CTC CTG AAC CAC TG-3'; nucleotide position 1757-1800) or a sense probe (5'- CAG TGG TTC AGG AGT TAG ACA GCC ATC ACA GTC TGC TCC TTA AC-3') were labeled with $\left[\alpha_{-}{ }^{35} \mathrm{~S}\right] \mathrm{dATP}$ (Dupont/NEN, Boston, MA, USA) on their 3'-ends and purified using MicroSpin G-50 columns (Amersham Bioscience). After prehybridization in hybridization buffer $(1 \times$ Dehnhardt's solution containing $1 \mathrm{M} \mathrm{NaCl}, 25 \mathrm{mM}$ Tris- $\mathrm{HCl}, 7.5 \mathrm{mM}$ EDTA, $12.5 \mathrm{mM}$ dithiothreitol, $10 \%$ dextransulfate, and $150 \mu \mathrm{g} /$ $\mathrm{ml}$ calf thymus DNA), slides were hybridized with labeled antisence probes or sense probes (control) overnight at $45^{\circ} \mathrm{C}$ in a humified chamber. Slides were then washed in $2 \times$ SSC for $10 \mathrm{~min}$ at room temperature, followed by two washes in $1 \times \mathrm{SSC}$ for $30 \mathrm{~min}$ at $45^{\circ} \mathrm{C}$ and in $2 \times \mathrm{SSC}$ for $30 \mathrm{~min}$ at room temperature. Dehydrated sections were then exposed to autoradiographic emulsion (Konica, Tokyo, Japan) for 2 weeks at $4{ }^{\circ} \mathrm{C}$. Sections were counterstained with hematoxylin and eosin after radioautography.

\section{Real-time quantitative RT-PCR}

mRNA levels of GH-R and IGF-I in the liver and ovary were determined using the ABI PRISM 7700 Sequence Detector (Perkin-Elmer). Total RNA was extracted from the liver and from the whole ovary. Additionally, using a stereomicroscope, oocytes at the most developed stage found in each ovary were selected, from which total RNA was extracted. They were treated with DNase 
(Invitrogen) and then reverse transcribed as described above. For GH-R mRNA, a specific primer pair (5'-CAC AGA CTT CTA CGC TCA GGT CA-3')/(5'-TGA GTT GCT GTC CAG GAG ACA-3') and a Taqman probe $\left(5^{\prime}\right.$-CAAT GTT ATG CCA ACT GGT GGT GTG GTG-3') were designed. IGF-I mRNA levels were determined by amplifications of $\mathrm{A}, \mathrm{D}$, and $\mathrm{E}$ domains with a specific primer pair $\left(5^{\prime}\right.$-CTG CTT CCA AAG CTG TGA GCT-3')/(5'-GAT CGA GAA ATC TTG GGA GTC TTG-3') and a Taqman probe (5'-CAG CGC CTT GAG ATG TAC TGT GCA CCT-3') as described previously (Kajimura et al. 2001). All primer pairs were designed using Primer Express software version 1.0 (Perkin-Elmer). Serial dilutions of the plasmid DNAs $\left(5 \times 10^{5} ; 6 \cdot 4\right.$ copies) containing the amplified fragments of target mRNAs were prepared as standard samples. PCR reaction contained $0 \cdot 2 \mu \mathrm{M}$ of each primer and $0.2 \mu \mathrm{M}$ Taqman probe, and $12.5 \mu \mathrm{l}$ Platinum Quantitative PCR Super-Mix-UDG (Invitrogen). The cycling parameter was as follows: $2 \mathrm{~min}$ at $95^{\circ} \mathrm{C}$ followed by 40 cycles at $95^{\circ} \mathrm{C}$ for $15 \mathrm{~s}$ and $60{ }^{\circ} \mathrm{C}$ for $1 \mathrm{~min}$. Data were analyzed by Sequence Detector version 1.6.3 (Perkin-Elmer) and expressed as the copy number of the target mRNA per $1 \mu \mathrm{g}$ total RNA.

\section{RIA}

Plasma levels of estradiol-17 $\beta\left(\mathrm{E}_{2}\right)$ were measured using a commercially available RIA kit (ImmunoChem Coated Tube $\mathrm{E}_{2}{ }^{125}$ I RIA Kit; ICN Biochemicals, Costa Mesa, CA, USA). Plasma levels of GH and IGF-I were measured by homologous RIAs as described elsewhere (Kajimura et al. 2001).

\section{Statistics}

Significance of differences was analyzed by one-way ANOVA followed by Fisher's protected least significant difference, using Stat View software (SAS Institute, Cary, NC, USA). Plasma levels of GH, mRNA levels of GH-R and IGF-I in the whole ovary and in the oocytes were first log-transformed, and then applied to one-way ANOVA since S.D. values were not equal. Levels of correlation were determined by calculating the correlation coefficient. Significance was set at $P<0 \cdot 05$.

\section{Results}

\section{cDNA cloning of tilapia GH-R}

PCR amplification of the tilapia liver cDNA with the degenerate primer set yielded a cDNA fragment (599 bp) sharing a high homology with other known GH-R cDNA sequences. Subsequently, tilapia GH-R cDNA was sequenced from $3^{\prime}-$ and $5^{\prime}$-RACE products (Fig. 1). The
GH-R cDNA consisted of 2807 bp which encoded 635 amino acids containing a putative signal peptide (27 amino acids), an extracellular domain (225 amino acids), a single transmembrane domain (24 amino acids), and an intracellular domain (359 amino acids). The homology analysis based on the amino acid sequences revealed that the tilapia GH-R showed the highest identity (74\%) to the GH-R of turbot, Scophthalmus maximus (Calduch-Giner et al. 2001). The tilapia GH-R also shared identities with the counterparts of seabream, Acanthopagrus schlegel (Tse et al. 2003) (73\%), goldfish, Carassius auratus (Lee et al. 2001) (49\%), masu salmon, Oncorhynchus masou (AB071216) (40\%), mouse, Mus musculus (AF120489) (34\%), and human, Homo sapiens (NM-000163) (35\%). On the other hand, the tilapia GH-R shared only $21 \%$ identity with tilapia PRL receptor (PRL-R) (L34783).

The deduced amino acid sequence had several characteristics conserved in known vertebrate GH-Rs (Fig. 2). The extracellular domain contained a characteristic FGEFS motif. The highly conserved box 1 and 2 regions were found within the intracellular domain of GH-R. The positions of six cysteine residues out of seven in the extracellular domain were highly conserved in the vertebrate GH-R with the exception of masu salmon. Three cysteine residues in the intracellular domain were also well conserved. There were six potential N-linked glycosylation sites, four of which were highly conserved in vertebrates. The nucleotide sequence reported in this paper has been deposited in the DDBJ/EMBL/GenBank DNA databases under Accession No. AB115179.

\section{Radioreceptor assay of tilapia GH-R}

The COS-7 cells transfected with the vector containing the GH-R insert showed specific binding to tilapia $\mathrm{GH}$, and the binding was blocked by excess amounts of unlabeled $\mathrm{GH}$ (Fig. 3A). Competitive binding assay showed that $\mathrm{GH}$, as compared with $\mathrm{PRL}_{177}$ and $\mathrm{PRL}_{188}$, bound to the GH-R with the highest sensitivity $\left(\mathrm{ED}_{50}=0.85 \mathrm{ng}\right)$. Labeled $\mathrm{GH}$ was displaced slightly by $\mathrm{PRL}_{177}\left(\mathrm{ED}_{50}=333 \cdot 3 \mathrm{ng}\right)$, but not by $\mathrm{PRL}_{188}$ (Fig. 3B).

\section{Tissue distribution of GH-R}

RT-PCR showed that the expected size (283 bp) of a single band was obtained in all the tissues examined (Fig. 4A). The highest expression was found in the liver, followed by the spleen and the heart. Northern blot hybridization showed a single transcript around $5.0 \mathrm{~kb}$, and liver expressed higher levels of GH-R mRNA than ovary (pooled sample at the different ovarian development, GSI $=1.67 \pm 0.68)$ (Fig. 4B).

\section{Localization of GH-R in the ovary}

In situ hybridization was performed to localize GH-R transcript in the ovary. Ovarian development in the tilapia 
$-331$

ggattgctggcggatgagggcgettgatcgctgcgcgaaacacactgcccactttttctgt ttaagcgacgtagcgtgtctctaccctccaagtggtctagacgataagcagcaaataaggcaaaaccgcaccaggaaagcacgcatcc tgagattgagtgatatgtaaaagtcgtcccggaaaggtctgagtcggaccgagcagtctgcagtgaagaagcaggactcgtaacccgtta gtgcttgcgctggccatcagatgagcaacttctgaaaagtaaatctgcgccgtgcttgcagttttcagctccacgcttcggaagaacatc

1 ATGGCTCTCTCGCCCTCCTCTAATCTCCTGATTCTTCTCATCCTTTCCTCCCTGGATTGGCTGCCCTCTCCAGGATCTACATTTCTCACT 90

$\begin{array}{lllllllllllllllllllllllllllllll}M & A & L & S & P & S & S & N & L & L & I & L & L & I & L & S & S & L & D & W & L & P & S & P & G & S & T & F & L & T\end{array}$

91 GACTGGGACCACACGACATCATCAGCTCTCATTGAGCCTCATTTTACTGAGTGTATATCAAGGGACCAGGAGACGTTCCACTGCTGGTGG 180

$\begin{array}{lllllllllllllllllllllllllllllllllll}\text { D } & W & D & H & T & T & S & S & A & L & I & E & P & H & F & T & E & C & I & S & R & D & Q & E & T & F & H & C & W & W\end{array}$

181 AGTCCCGGCAGCTTCCACAACCTCTCCTCCCCTGGAGCACTCCGAGTCTTCTACCTTAAGAAAGAGTCTCCTACCAGCCAGTGGAAGGAG 270

$\begin{array}{llllllllllllllllllllllllllllllll}S & P & G & S & F & H & N & L & S & S & P & G & A & L & R & V & F & Y & L & K & K & E & S & P & T & S & Q & W & K & E\end{array}$

271 TGTCCTGAGTATATCCATTCAAATAGGGAATGTTTCTTTGATGAAGCTCACACATCCATATGGATCACTTACTGCATGCAGCTTCGCACT 360

$\begin{array}{llllllllllllllllllllllllllllllll}C & P & E & Y & I & H & S & N & R & E & C & F & F & D & E & A & H & T & S & I & W & I & T & Y & C & M & Q & L & R & T\end{array}$

361 CAAAACAACATCACCTATTTCAATGAGGATGACTGTTTCAGTGTGGAGAATATTGTACGTCCTGACCCGCCAGTGAATTTAAACTGGACC 450

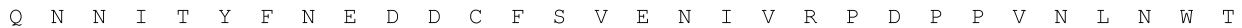

451 CTGCTGAATATAAGTCCTTCCGGGCTAAATTATGATGTCATGATTAACTGGGAGCCCCCACCTACTGCTGATGTTAGGTTGGGATGGATG 540

$\begin{array}{llllllllllllllllllllllllllllllll}L & L & N & I & S & P & S & G & L & N & Y & D & V & M & I & N & W & E & P & P & P & T & A & D & V & R & L & G & W & M\end{array}$

541 CGTGTGGAGTATGAGTTGCAGTACAGAGAGAGAAATACCACAAACTGGGAAGCATTGGACATTCAGCGACAGTCTCATCAGACAATCTAC 630

$\begin{array}{lllllllllllllllllllllllllllllllllll}R & V & E & Y & E & L & Q & Y & R & E & R & N & T & T & N & W & E & A & L & D & I & Q & R & Q & S & H & Q & T & I & Y\end{array}$

631 GGTCTGCGCTTAGGAAAAGAATATGAAGTACACATCCGCTGCAGGATGCAGGCTTTCATTAAATTTGGCGAGTTCAGTGAATCCATCTTC 720

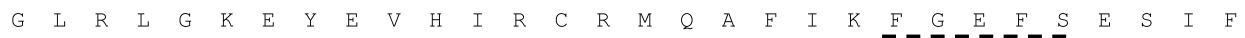

721 ATTCAAGTGACTGAGATTCCTAGCACAGAGTCTACTGTCCATCTCACACTGGTTCTTGTATTTGGGACTGTGGGTATCCTCATACTCATC 810

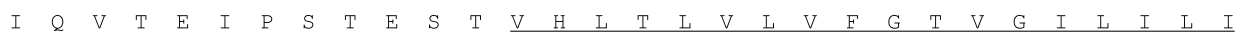

811 AтGCTCATAGTCATCTCTCAGCAGAACCGATTAATGATATTCCTGCTGCCGCCTGTTCCTGCACCCAAAATCAAAGGCATCGATTCAGAG 900

\begin{tabular}{llllllllllllllll|llllllllllllllll}
$M$ & $L$ & $I$ & $V$ & $I$ & $S$ & $Q$ & $Q$ & $N$ & $R$ & $L$ & $M$ & $I$ & $F$ & $L$ & $L$ & $P$ & $P$ & $V$ & $P$ & $A$ & $P$ & $K$ & $I$ & $K$ & $G$ & $I$ & $D$ & $S$ & $E$
\end{tabular}

901 CTATTGAAGAAGGGGAAGCTGGATGAGCTGAATTTTATGCTGAGTGGTGGAGGAATGGATGGCCTGCCCATTTATGCACCAGATTTCTAC 990

$\begin{array}{llllllllllllllllllllllllllllll}L & L & K & K & G & K & L & D & E & L & N & F & M & L & S & G & G & G & M & D & G & L & P & I & Y & A & P & D & F & Y\end{array}$

991 CAAGACGAGCCGTGGGTGGAGCTCATGGAGGTCGATGAGACAGAGGATGTAGATAATGGAGAGAAGAAGGATAACTGGGGCTCAGACACC 1080

\& $\quad \mathrm{D} \quad$\begin{tabular}{|llllllllllllllllllllllllllllll} 
& $\mathrm{E}$ & $\mathrm{P}$ & $\mathrm{W}$ & $\mathrm{V}$ & $\mathrm{E}$ & $\mathrm{L}$ & $\mathrm{M}$ & $\mathrm{E}$ & $\mathrm{V}$ & $\mathrm{D}$ & $\mathrm{E}$ & $\mathrm{T}$ & $\mathrm{E}$ & $\mathrm{D}$ & $\mathrm{V}$ & $\mathrm{D}$ & $\mathrm{N}$ & $\mathrm{G}$ & $\mathrm{E}$ & $\mathrm{K}$ & $\mathrm{K}$ & $\mathrm{D}$ & $\mathrm{N}$ & $\mathrm{W}$ & $\mathrm{G}$ & $\mathrm{S}$ & $\mathrm{D}$ & $\mathrm{T}$
\end{tabular}

1081 CAGAAACTCCTGGGTCAGTCCCAACCTGTCAGTCAACACATCAACATAAACTGCTCAAATTCAGTCAGTGGTCCGGATGCTGAGTCATCC 1170

$\begin{array}{lllllllllllllllllllllllllllllll}\ell & K & L & L & G & Q & S & Q & P & V & S & Q & H & I & N & I & N & C & S & N & S & V & S & G & P & D & A & E & S & S\end{array}$

1171 CAGGCCACCTGTTACAACACAGATCTCCCTGAAGAAGAAACACAAATGCTGATGGCCACGCTTCTACCAGGACAACCTGATGAAGAGGAA 1260

Q

1261 AсCTCCCTTGATACTGTAGAAAGATCCTCAGCCTCTGAGACAGGTGAAAGACAGCTCATCCAAACCCAAACCAGAGGGCCCCAGACCTGG 1350

$\begin{array}{lllllllllllllllllllllllllllllll}T & S & L & D & T & V & E & R & S & S & A & S & E & T & G & E & R & Q & L & I & Q & T & Q & T & R & G & P & Q & T & W\end{array}$

1351 GTCAACACAGACTTCTACGCTCAGGTCAGCAATGTTATGCCAACTGGTGGTGTGGTGTTGTCTCCTGGACAGCAACTCAGAATCCAGGAG 1440

$\begin{array}{llllllllllllllllllllllllllllllllllll}V & N & T & D & F & Y & A & Q & V & S & N & V & M & P & T & G & G & V & V & L & S & P & G & Q & Q & L & R & I & Q & E\end{array}$

1441 AGCATCTCAGCCGCCGAGAAGGAAACAAAAAAGAAGCGGAAAGAGAGTGAAGACAGCGAGGAGTCTGAGGAACGGAAGCAAAAAGAGCCA 1530

$\begin{array}{llllllllllllllllllllllllllllllll}S & I & S & A & A & E & K & E & T & K & K & K & R & K & E & S & E & D & S & E & E & S & E & E & R & K & Q & K & E & P\end{array}$

1531 CAGTTTCAGCTGCTAGTAGTGGATCCAGAAGGAAGTGCCTACAGTACAGAGAGCAGTATCCAGCAAATCAGCACTCCTCCCCCTAGCTCT 1620

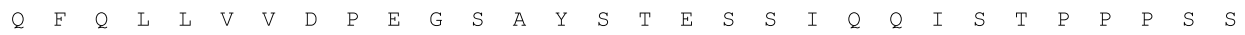

1621 CCCATGCCCGGTGAGGGGTACCACATCATACATCCTCAGCCAGTGGAGCCCAGACCTGCAGCCACAACGGAGCTTAATCAGTCACCTTAC 1710

$\begin{array}{lllllllllllllllllllllllllllllllllll}P & M & P & G & E & G & Y & H & I & I & H & P & Q & P & V & E & P & R & P & A & A & T & T & E & \text { L } & N & Q & S & P & Y\end{array}$

1711 ATTATTCCTGACTCTCCCCAGTTTTTGGCTCCTGTTGCAGACTACACAGTGGTTCAGGAGTTAGACAGCCATCACAGTCTGCTCCTTAAC 1800

$\begin{array}{lllllllllllllllllllllllllllllll}I & I & P & D & S & P & Q & F & F & A & P & V & A & D & Y & T & V & V & Q & E & L & D & S & H & H & S & L & L & L & N\end{array}$

1801 CCGCCTTGCCACCAGACCCCCCCTCCCTGCCTGCCACAGCACCCACTCAAGGCACCTATGCCTGTGGGTACATTACCCCAGACCTGCTG 1890

$\begin{array}{lllllllllllllllllllllllllllllllll}\mathrm{P} & \mathrm{P} & \mathrm{C} & \mathrm{H} & \mathrm{Q} & \mathrm{T} & \mathrm{P} & \mathrm{P} & \mathrm{P} & \mathrm{C} & \mathrm{L} & \mathrm{P} & \mathrm{Q} & \mathrm{H} & \mathrm{P} & \mathrm{L} & \mathrm{K} & \mathrm{A} & \mathrm{P} & \mathrm{M} & \mathrm{P} & \mathrm{V} & \mathrm{G} & \mathrm{Y} & \mathrm{I} & \mathrm{T} & \mathrm{P} & \mathrm{D} & \mathrm{L} & \mathrm{L}\end{array}$

1891 GGGAACCTCTCACAATGAaatgacaatgacatcagacctttacgtgtaaggctgattcaccaggaagttacctacagtcgtcctacccga 1980

G N $\quad \mathrm{N} \quad \mathrm{S} \quad \mathrm{Q}$ *

1981 ttcccgttggaaactcccagcacactgggtggctgagatgtgcacgggtgtctattttcagaggatgctgaaaggcagatataaaaggct 2070

2071 Acaagatactctcttaacttctttgcatctgctaaagcagttctttttgaggcagccaaatattaacatcacaaaccaaatgcacagtt 2160

2161 tgctctgtttcgtcaacacctcatgcatccatgcatgattacagtgagccaagcaaacataatatcaatgcttaactgccttgtgttgca 2250

2251 ttgtatctctggcttattgtgtccagagcaatgacgctgttacagtcttaattttacagagtgctttcagtgcatgaccgatggtgtgag 2340

2341 ttttcacaccaaacaaagtcattgctgacggtgatgctgtttaacccacgaggtactttatcagtttatcaatagaccgttcctatctt 2430

2431 tcttaactcatcatatcatattagcacttcactagagatatattt

2476

Figure 1 The nucleotide sequence of cDNA encoding tilapia GH-R and the deduced amino acid sequence.

Nucleotide numbers are shown on both sides. The FGEFS motif is underlined with a broken line, and the

transmembrane domain with a solid line. Box 1 and 2 regions are shown in shaded rectangles. The stop codon is

marked with an asterisk. 


\begin{tabular}{|c|c|}
\hline & * $\star *$ \\
\hline Seabream & MSVSSSSSSSSSSTSNLLLLLLVSSLDWLSTRGSALAMD--HMTSSAPVGPHFTECVSREQETERCWWSPGGFHNLSSPGALRVFYLKKD \\
\hline Goldfish & ------ MAYSLLLSLLYLGMLCGNGLVSARSELFTPD------PSRGPHFTGCRSREQETERCWWSAGIFQNLTEPGALRVFYMTKH \\
\hline Rat & MDLWRVFLTLALAVSSDMF PGSGATPATLGKASPVLQRINPSLRESSSGKPRFTKCRS PELETESCYWTEGDDHNLKVPGS IQLYYARRI \\
\hline Human & MDLWQLLLTLALAGSSDAFSGSEATAAILSRAPWSLQSVNPGLKTNSSKEPKFTKCRSPERETESCHWTDEVHHGTKNLGPIQLFYTRRN \\
\hline Seabream & SPTS--EWKECPEYSHLKR-ECFFDVNHTSVWVPYCMQLRGQNNVTYLDEDYCF \\
\hline Goldfish & ALS---EWQECPDYTRTVKNECYFNKTFTQIWTSYCIQLRSVR-ENITYDEACFTVENIVHPDPPIGLNWTLLNVSRSGLHYDILVRWAP \\
\hline Masu salmon & RNISPKEWGECPRYADRTN-FCFFNESYTKVWMTYSVQFRSGD-QDILYDEVIFTVEDIVEPDPPIALNWTLINMGLTGSHFDIMLSWEP \\
\hline Rat & AHEWTPEWKECPDYVSAGANSCYFNSSYTS IWI PYCI KLTTNG---DLLDEKCFTVDE IVQPDPPIGLNWTLLNISLPGIRGDIQVSWQP \\
\hline Human & TQEWTQEWKECPDYVSAGENSCYFNSSFTS IWI PYCIKLTSNG---GTVDEKCFSVDE IVQPDPPIALNWTLLNVSLTGI HADIQVRWEA \\
\hline Masu salmon & PHSADVSMGWMTLQYEVQYREVNSTLWRTVDLEKGMQRSLYGLRSNTYNEVRVRCKTLASRNFGEFSDS IFIHIPTK--------ESRFP \\
\hline Rat & PPSADVLKGWI ILEYEIQYKEVNETKWKTMSP IWSTSVPLYSLRLDKEHEVRVRSRQRSFEKYSEFSEVLRVTFPQMDTLAACEEDFRFP \\
\hline Human & PRNADIQKGWMVLEYELQYKEVNETKWKMMDPILTTSVPVYSLKVDKEYEVRVRSKQRNSGNYGEFSEVLYVTLPQMS-QFTCEEDFYFP \\
\hline & 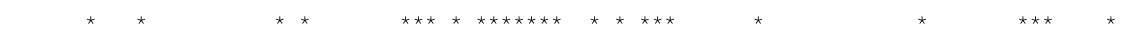 \\
\hline pia & LTLVLVFGTVGILILIMLIVISQQNRLMIFLLPPVPAPKIKGIDSELLKKGKLDELNFMLSGGGMDGLPIYAPDFYQDEPWVELMEVDET \\
\hline ot & LAVVLVFGIVGILILIMLI IVSQQHRLMMI LLPPVPAPKI KGIDPELLKKGKLDELNLFLSGGGMGGLSTYAPDFYQDEPWVEFIELDT- \\
\hline Seabream & FKLALIFGVLGILILILLIGISQQPRLMMILLPPVPAPKIKGIDPELLKKGKLDELNFILSGGGMGGLSTYAPDFYQDEPWVEFIEVDA- \\
\hline Goldfish & TTLVLIFGMIGVVILLVLLIF SQQQRLMVIFLPPIPAPKIKGIDPELLKNGKLDQLNSLLSSQ-----DMYKPDFYHEDPWVEFIQLDLD \\
\hline Masu salmon & VTVLLVFAALGLAVILILVIYSQQQKLMMILLPPI PGPKIKGIDPELFKKGKLAELTS ILGDHP-----DLRPELYGEDPWVEFIELDME \\
\hline Rat & WFLIIIFGIFGVAVMLFVVIFSKQQRIKMLILPPVPVPKIKGIDPDLLKEGKLEEVNT ILGIHDN-----YKPDFYNDDSWVEFIELDID \\
\hline Human & WLII I IFGIFGLTVMLFVFLFSKQQR IKMLILPPVPVPKIKG IDPDLLKEGKLEEVNT ILAIHDS-----YKPEFHSDDSWVEFIELDID \\
\hline & ** $\quad * \quad \quad$. \\
\hline Tur & ------------- PEGGEASLDVEEGASASERSKRALIQTQTAGPQTWVNTDFYAQVSNVMPSGGVVLSPC \\
\hline Seabream & ------------ PEAGEDSFDVVESAPVIERSERPLMQTQTGGPQTWVNTDFYAQVSNVMP SGGVVLSPGQQLRLQESTSATEDE \\
\hline Goldfish & ---------------PLVSRSSSS I PDLGVQQTSEVKETP IQKQPAVPSWVNMDFYAQVSDFTPAGGVVLSPGQLNSS LEKKKEEENE \\
\hline Masu salmon & --------------------PSLEPSGASTEASSPVQTPTTGMTLWAVPGREDLYTQVSEVRPSGEVLLMPEEQSKVEKDAEEKAKE \\
\hline Rat & NLKNSP-YDASLGSLHPS ITLTMEDKPQPLLGSETESTHQLPSTPMSSPVSLANIDFYAQVSDITPAGGVVLSPGQKIKAGLAQGNTQLE \\
\hline Human & NQNNS PYHDACPATQQPSVIQAEKNKPQPLPTEGAESTHQAAH IQLSNPSS LSNIDFYAQVSDITPAGSVVLSPGQKNKAGMSQCDMHPE \\
\hline & \\
\hline & TKKKRKESEDSEESEERKQKEPQFQLLVVDPEGSAYSTESS \\
\hline & QKNIKESEDR--GDEKKQKELQFQ \\
\hline ream & AQKKGKGSED---SEVKAQKELQFQLLVVDPEGSGYTTESNARQ \\
\hline Goldfish & KKIQFQLVSDG------------------AYTSENTARQLSANVP----SSPGPEQGYQTFPTQAVEG \\
\hline Masu salmon & GKEKEKPRKE------------FQLLVVNADGGGYTTELD \\
\hline Rat & VAAPCQENYSMN--------------------SAYECESDAKKCIAAAPHMEATTCVKPSFNQEDIYITTES \\
\hline Human & 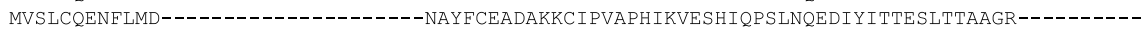 \\
\hline & \\
\hline & YIIPDSP--QFFAPVADYTVVQELDSHHSLLLNPPCHQ-TPPPCLPQHPLKAP--MPVGYITPDLLGNLSQ \\
\hline & YIAPDSPQFQFSAPVSDYTVVQEVDTEHSLLLNPPPHQ-STP PCLPQHPFKALPAMPVGYITPDLLGHLSP \\
\hline Seabream & YILPDSPQSQFFAPVADYTVVQEVDSQHSLLLNPPPRQ-SPPPCLPHHPAKALPAMPVGYVTPDLLGNLSP \\
\hline Goldfish & YLLPEAPPSPILPPVSDYTVVQEVDAQHSLLLNPPSSQPAICPHSPNKHLPAMPTMPMGYLTPDFLGNLTP \\
\hline Masu salmon & -PIPPASPVSPLLPLSVYTMVEGVDRQNSLLLKPSPPP---APQPVLTKLPLPTGTPEGYLTPDLLGNITP \\
\hline Rat & -SETADTAP-DAEPVPDYTTVHTVKSPRGLILNATALP---------LPDKKKFLSSCGYVSTDQLNKIMQ \\
\hline Human & -PGTGEHVPGSEMPVPDYTSIHIVQSPQGLILNATALP---------LPDKE-FLSSCGYVSTDQLNKIMP \\
\hline
\end{tabular}

Figure 2 Alignment of the amino acid sequences of GH-R in vertebrates. The alignment was performed using the CLUSTAL W multiple sequences alignment program (Thompson et al. 1994). Identical amino acids are indicated by asterisks above the sequences. Gaps are shown as dashes. The cysteine residues are shown in solid rectangles, and the putative $\mathrm{N}$-linked glycosylation sites in shaded rectangles.

is asynchronous, and thus oocytes at different developmental stages are found simultaneously in a single ovary. In the immature ovary, intense signals were observed in the cytoplasm and nucleus of the oocyte at the perinucleolus stage and the yolk vesicle stage (Fig. 5A). In the follicles surrounding the primary yolk globule stage, both granulosa and theca cells contained GH-R transcripts
(Fig. 5B). Strong signals were found in the somatic cells surrounding the follicles (Fig. 5C). Oocytes at the late yolk globule stage were distinguished by the presence of chorion observed on the vitelline membrane (marked with an asterisk in Fig. 5D and F). GH-R transcripts were also found in the granulosa and theca cells at the secondary yolk globule stage (Fig. 5D). No signal was 

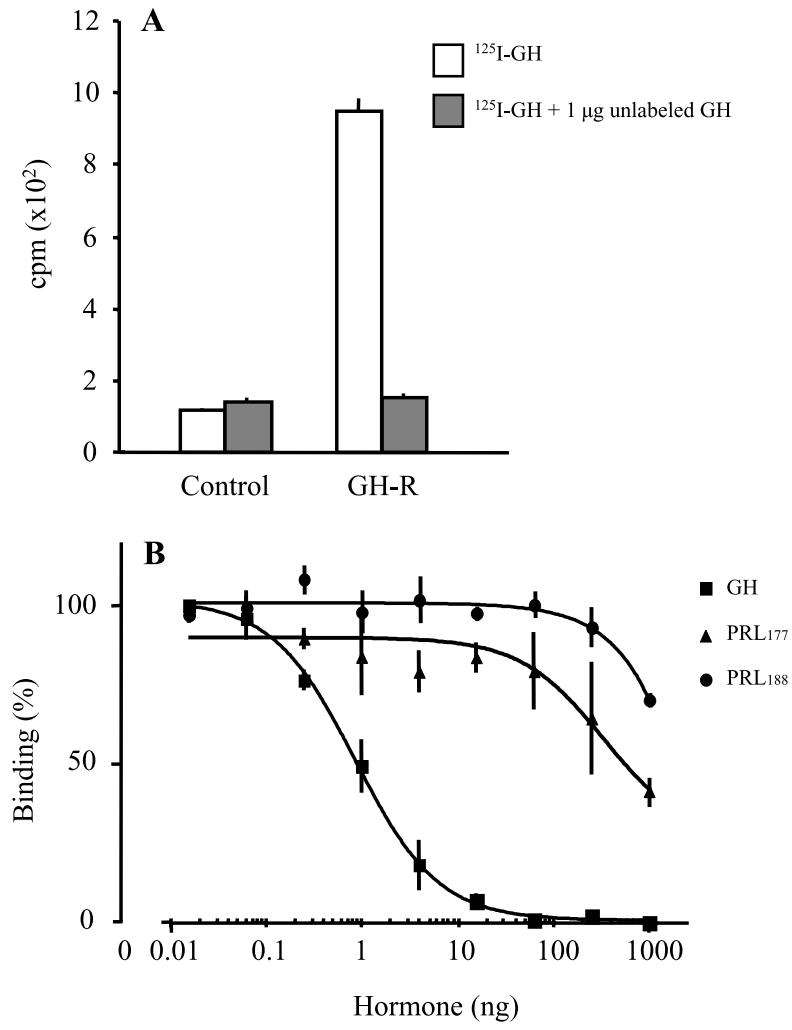

Figure 3 Functional analysis of tilapia GH-R cDNA. (A) Binding of ${ }^{125}$ I-GH to COS-7 cells transfected with vector containing GH-R cDNA (GH-R) or vector only (control) in the absence (open bars) or presence (shaded bars) of $1 \mu \mathrm{g}$ unlabeled tilapia $\mathrm{GH}$. (B) Competitive binding assay with serial dilutions of unlabeled tilapia $\mathrm{GH}, \mathrm{PRL}_{177}$, and $\mathrm{PRL}_{188}$. Values are means \pm S.E.M. seen in the control sections incubated with the sense probe (Fig. 5E and F).

Changes in plasma hormone levels during ovarian development

Table 1 shows the changes in hormone levels in the plasma during ovarian development. Fish were divided into three groups based on the developmental stages of the ovaries by histological analysis as follows: immature, ovaries contained mainly oocytes at the perinucleolus stage and the yolk vesicle stage (GSI: 0.52 $\pm 0.08 \%$ ); maturing, ovaries contained oocytes at the perinucleolus stage, the yolk vesicle stage, and the primary yolk globule stage (GSI: $1 \cdot 50 \pm 0 \cdot 16 \%)$; matured, ovaries contained various stages of ovarian development including the secondary yolk globule stage (GSI: $2 \cdot 93 \pm 0 \cdot 32 \%$ ). Plasma $\mathrm{E}_{2}$ levels were low in immature fish but increased significantly $(P<0 \cdot 05)$ in maturing and matured fish. A significantly $(P<0 \cdot 05)$ higher level of plasma $\mathrm{GH}$ was found in the matured fish than in the maturing fish. No significant change was seen in plasma IGF-I level throughout ovarian development.

Gene expression profiles of GH-R and IGF-I during ovarian development

To further quantify the mRNA levels of GH-R and IGF-I at the different ovarian developmental stages, real-time quantitative RT-PCR was employed. As shown in Table 2, there were no significant changes in GH-R and IGF-I mRNA levels in the liver among the three stages. No significant changes were found in GH-R and IGF-I

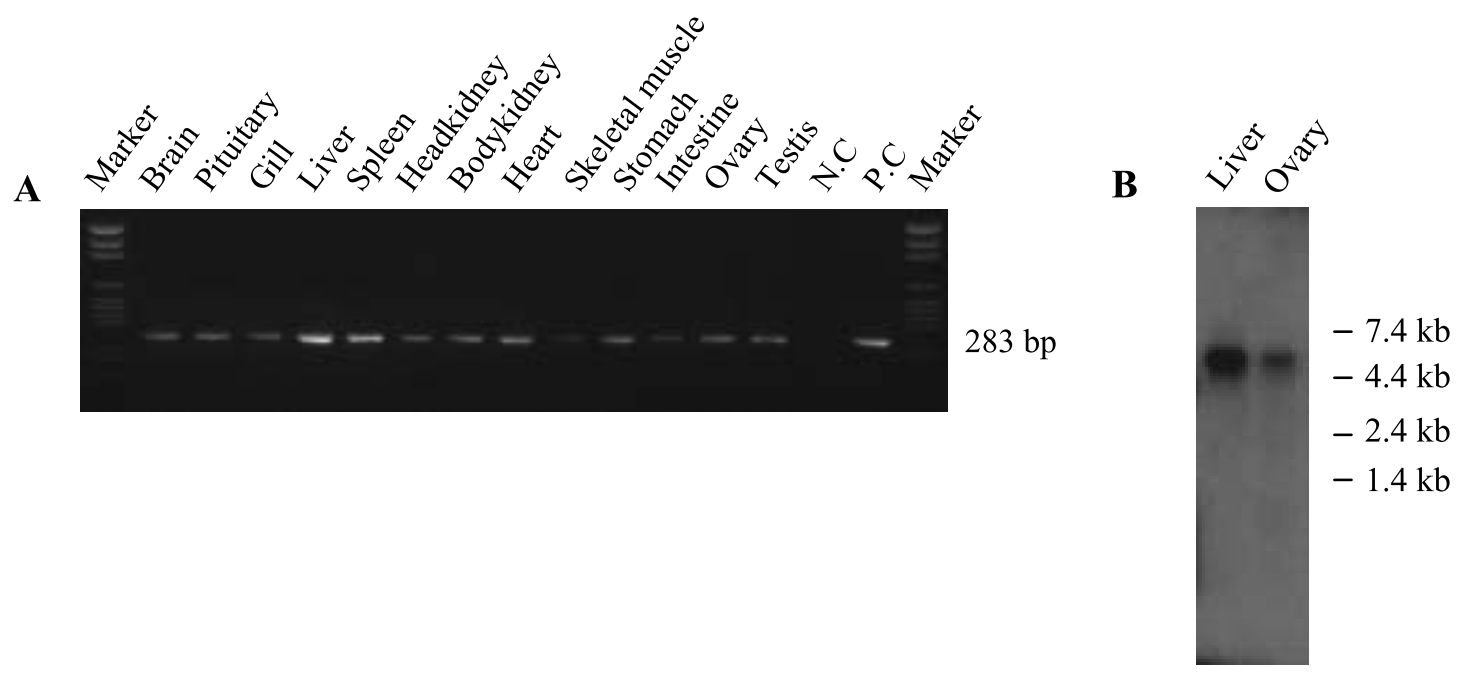

Figure 4 Tissue distribution and transcripts of GH-R gene in the tilapia. (A) RT-PCR analysis with specific primers. N.C and P.C represent negative control and positive control respectively. The molecular markers are shown on both sides of the gel. (B) Northern blot analysis of tilapia GH-R in the liver and ovary (pooled sample at the different ovarian developments, $\mathrm{GSI}=1 \cdot 67 \pm 0 \cdot 68$ ). The molecular marker is presented on the right. 

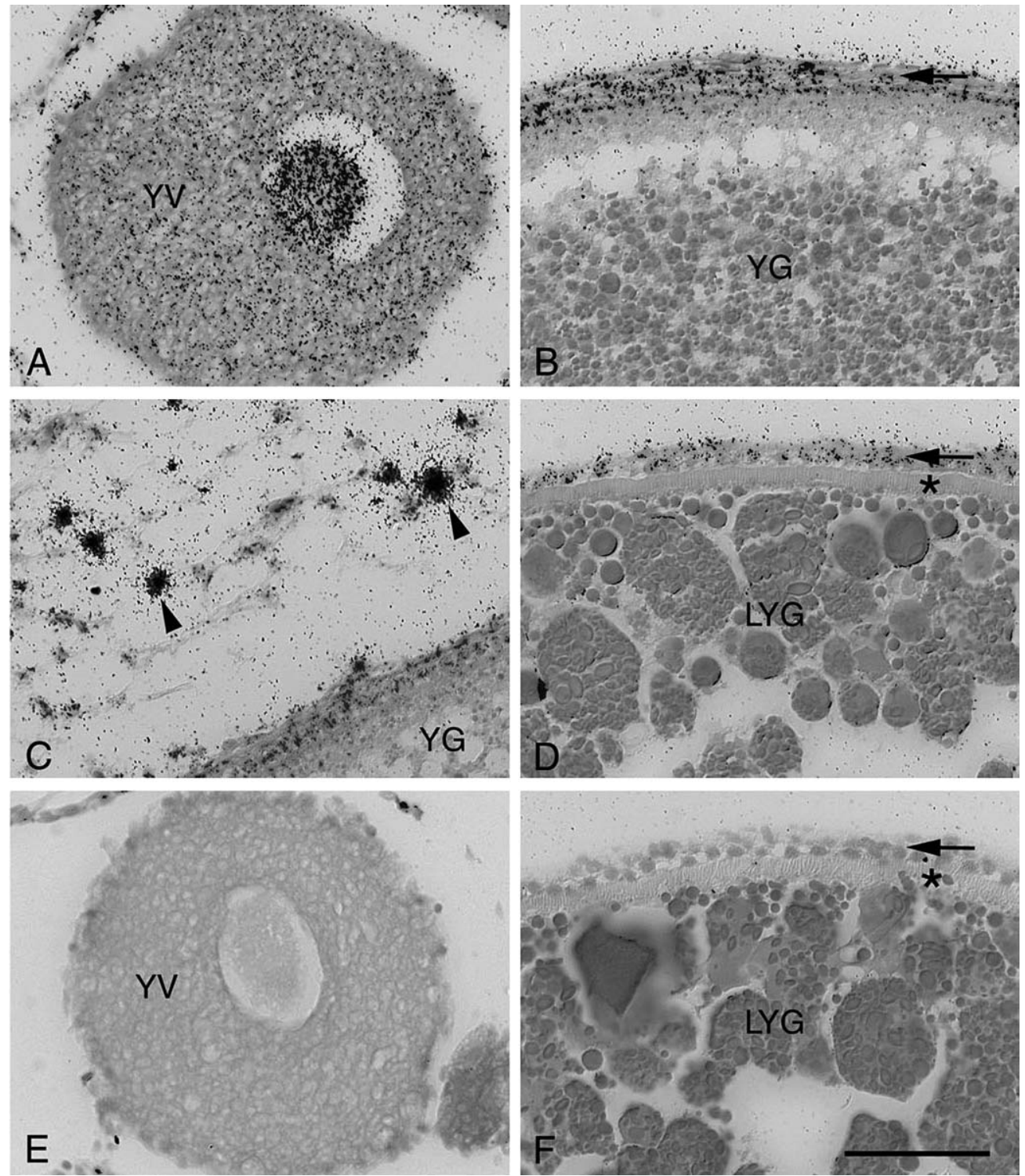

Figure 5 In situ hybridization of GH-R in the tilapia oocytes. (A) Immature oocytes at the yolk vesicle stage (YV). (B) Vitellogenic oocytes at the primary yolk globule stage (YG). Follicles (granulosa and theca cells) contained GH-R transcripts (arrow). (C) Somatic cells surrounding follicles at the primary yolk globule stage (arrowheads). (D) Vitellogenic oocytes at the late yolk globule stage (LYG). Chorion is marked with an asterisk. Follicle is indicated with an arrow. (E) Immature oocytes at the yolk vesicle (YV) stage hybridized with sense probe (negative control). (F) Vitellogenic oocytes at the late yolk globule (LYG) stage hybridized with sense probe (negative control). Chorion is marked with an asterisk. Scale bar $=50 \mu \mathrm{m}$.

mRNA levels in the whole ovary. Tilapia ovary simultaneously contains oocytes at different developmental stages. When oocytes at the same developmental stage were selected from each ovary, the mRNA level of GH-R was significantly $(P<0 \cdot 05)$ greater in the immature oocytes, as compared with matured oocytes. Similarly, IGF-I mRNA level was significantly $(P<0 \cdot 05)$ higher in the immature oocytes, and decreased in the maturing and matured oocytes.
Figure 6 shows the correlation analysis between mRNA levels of GH-R and IGF-I in the liver and ovary (GSI: 0.59-4.49\%). Hepatic GH-R mRNA showed a significant positive correlation with hepatic IGF-I mRNA (Fig. 6A: $\left.\mathrm{R}^{2}=0 \cdot 84, P<0 \cdot 001\right)$. In addition, ovarian GH-R mRNA was positively correlated with ovarian IGF-I mRNA (Fig. 6B: $\mathrm{R}^{2}=0 \cdot 72, P<0 \cdot 001$ ). However, no significant correlation was found between hepatic GH-R and ovarian GH-R (Fig. 6C: $\mathrm{R}^{2}=0 \cdot 02$ ). Similarly, hepatic 
Table 1 Changes in GSI, plasma levels of $E_{2}, G H$, and IGF-I during ovarian development. Values are means \pm S.E.M. $(n=4-9)$

\begin{tabular}{|c|c|c|c|}
\hline \multirow[b]{2}{*}{ Index } & Immature & Maturing & Matured \\
\hline & & & \\
\hline GSI (\%) & $0.52 \pm 0 \cdot 08^{a}$ & $1 \cdot 50 \pm 0 \cdot 16^{b}$ & $2 \cdot 93 \pm 0 \cdot 32^{\mathrm{C}}$ \\
\hline Plasma $E_{2}(\mathrm{ng} / \mathrm{ml})$ & $7 \cdot 35 \pm 2 \cdot 35^{a}$ & $20 \cdot 63 \pm 4.08^{b}$ & $18 \cdot 42 \pm 5 \cdot 82^{b}$ \\
\hline Plasma GH (ng/ml) & $7 \cdot 18 \pm 5 \cdot 12^{a, b}$ & $3 \cdot 03 \pm 0.56^{a}$ & $8.09 \pm 2.09^{b}$ \\
\hline Plasma IGF-I (ng/ml) & $174 \cdot 7 \pm 14 \cdot 1^{\mathrm{a}}$ & $136 \cdot 4 \pm 18 \cdot 2^{a}$ & $134 \cdot 7 \pm 8 \cdot 2^{\mathrm{a}}$ \\
\hline
\end{tabular}

Different letters $(\mathrm{a}, \mathrm{b}, \mathrm{c})$ indicate significant difference at $P<0 \cdot 05$.

IGF-I mRNA was not correlated with ovarian IGF-I mRNA (Fig. 6D: $\mathrm{R}^{2}=0 \cdot 008$ ).

\section{Discussion}

To our knowledge, this is the first report on specific localization of GH-R mRNA in the fish ovary. Intense signals of GH-R transcripts were observed in the cytoplasm and nucleus of the immature oocytes, and in the granulosa and theca cells surrounding vitellogenic oocytes of the tilapia. There was no correlation between hepatic GH-R mRNA and ovarian development. On the other hand, the high level of GH-R mRNA in the immature oocytes was well correlated with the high level of IGF-I mRNA in the oocytes, indicating that the GH/IGF-I axis in the ovary may be involved in the early stages of oocyte development, possibly under a different regulatory mechanism of GH-R gene expression from that of the liver.

The cloned tilapia GH-R cDNA contained several characteristics conserved among vertebrate GH-R cDNAs. These include the FGEFS motif, which replaces the WSXWS motif found in other cytokine receptors including PRL-R, but conserved among all known fish GH-R to date. The intracellular domain has a highly conserved proline-rich motif named box 1 , which is known to be important for interacting with the Jak kinase-mediating signals of ligands such as GH and PRL to the signal transducer and activator of the transcription family (Frank et al. 1994). The intracellular domain also contains the box 2 region, involved in the internalization of the receptor (Govers et al. 1999). However, the conserved sequence (WVEFI) is changed to WVELM in the tilapia, even though it is a relatively conservative change in terms of polarity of amino acid. In fact, the amino acid sequence in box 2 is less conservative than that in box 1 among the known GH-R sequences in vertebrates, but how the structural changes affect the function of GH-R remains unknown. Comparative analysis of fish GH-R structures and those of tetrapods will further reveal the core sequence essential for GH-R functions.

Binding assays using COS-7 cells were performed to confirm the function of the cloned cDNA. ${ }^{125}$ I-Labeled $\mathrm{GH}$ was displaced by homologous tilapia GH and slightly by $\mathrm{PRL}_{177}$, one of two homologous tilapia PRLs $\left(\mathrm{PRL}_{188}\right.$ and $\left.\mathrm{PRL}_{177}\right)$, but not by $\mathrm{PRL}-{ }_{188}$. The $\mathrm{ED}_{50}$ of $\mathrm{GH}$ in the binding assay using $0.85 \mathrm{ng}$ was similar to the results from membrane fractions of tilapia liver $(0.68 \mathrm{ng})$ (Shepherd et al. 1997), suggesting that the cloned tilapia GH-R cDNA is the functional GH-R of the tilapia. Shepherd et al. (1997) reported that $\mathrm{PRL}_{177}$ exhibits somatotropic actions by acting as a competitive ligand for GH-Rs on the hepatic membrane and promotes IGF-I gene expression in fresh water, where $\mathrm{PRL}_{177}$ reaches sufficient levels to displace GH-Rs (50-fold less than GH). In the present study, $\mathrm{PRL}_{177}$ had much lower potency (392-fold less than $\mathrm{GH})$ than the previous report using hepatic membrane fraction (Shepherd et al. 1997). The difference in crossreaction between the two experiments might be due to the different membrane preparations or different batches of $\mathrm{PRL}_{177}$.

Tissue distribution studies indicate the substantial amounts of GH-R transcripts in a variety of extrahepatic tissues including the ovary, in agreement with other teleost species (Calduch-Giner et al. 2001, Lee et al. 2001, Tse et al. 2003). Furthermore, a single transcript of GH-R was detected in the liver and ovary by Northern blot analysis. In rodents, an alternative splicing variant of GH-R gene expresses a short form of mRNA encoding GH-binding protein (GHBP) (Smith et al. 1989). On the other hand, the human and the rabbit express a single mRNA of GH-R, and the GHBP was produced

Table 2 Changes in mRNA levels of GH-R and IGF-I during ovarian development. Values are means \pm S.E.M. $\left(\times 10^{5}\right.$ copies $/ \mu$ g total RNA; $\left.n=4-9\right)$

\begin{tabular}{|c|c|c|c|c|}
\hline & Tissue & Immature & Maturing & Matured \\
\hline \multicolumn{5}{|l|}{ Index } \\
\hline \multirow[t]{3}{*}{ GH-R } & Liver & $12 \cdot 26 \pm 1 \cdot 57^{a}$ & $10 \cdot 13 \pm 2 \cdot 99^{a}$ & $8 \cdot 45 \pm 2 \cdot 56^{a}$ \\
\hline & Whole ovary & $3 \cdot 14 \pm 1 \cdot 32^{a}$ & $3 \cdot 80 \pm 0 \cdot 40^{a}$ & $4 \cdot 97 \pm 1 \cdot 36^{\mathrm{a}}$ \\
\hline & Oocytes & $1 \cdot 62 \pm 0.28^{a}$ & $1 \cdot 09 \pm 0 \cdot 68^{a, b}$ & $0 \cdot 16 \pm 0.03^{b}$ \\
\hline \multirow[t]{3}{*}{ IGF-I } & Liver & $15 \cdot 32 \pm 5 \cdot 42^{a}$ & $10 \cdot 59 \pm 4.05^{a}$ & $10 \cdot 48 \pm 3 \cdot 36^{a}$ \\
\hline & Whole ovary & $3 \cdot 27 \pm 0 \cdot 51^{a}$ & $1 \cdot 82 \pm 0 \cdot 36^{\mathrm{a}}$ & $3 \cdot 94 \pm 1 \cdot 12^{\mathrm{a}}$ \\
\hline & Oocytes & $1 \cdot 27 \pm 0 \cdot 35^{a}$ & $0 \cdot 32 \pm 0 \cdot 15^{b}$ & $0.13 \pm 0.03^{b}$ \\
\hline
\end{tabular}

Different letters $(a, b)$ indicate significant difference at $P<0 \cdot 05$. 
A

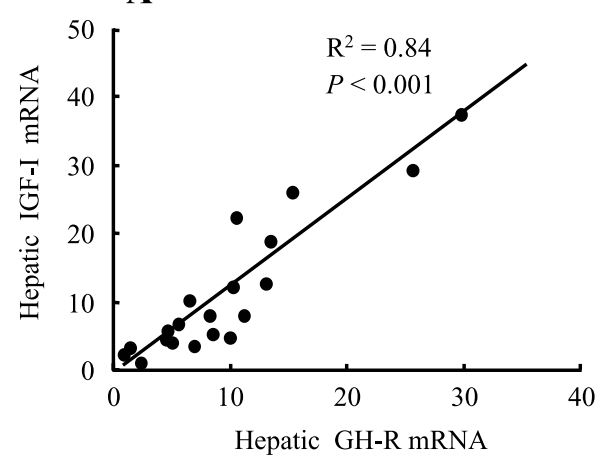

C

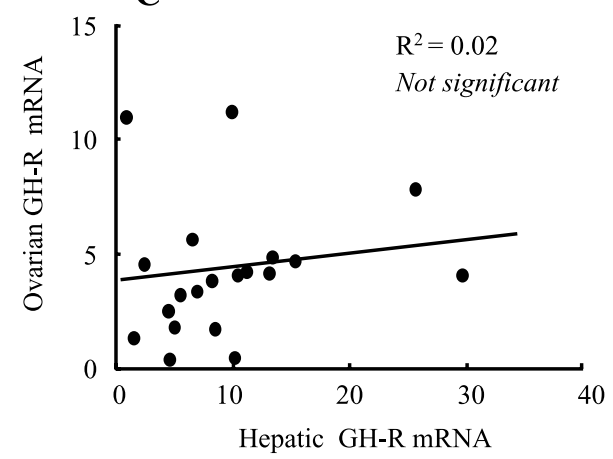

B

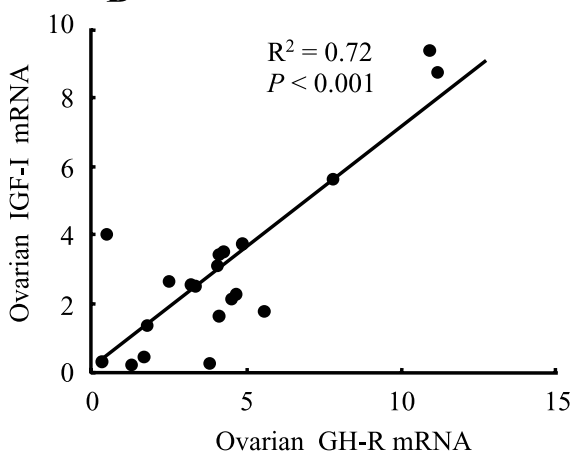

D

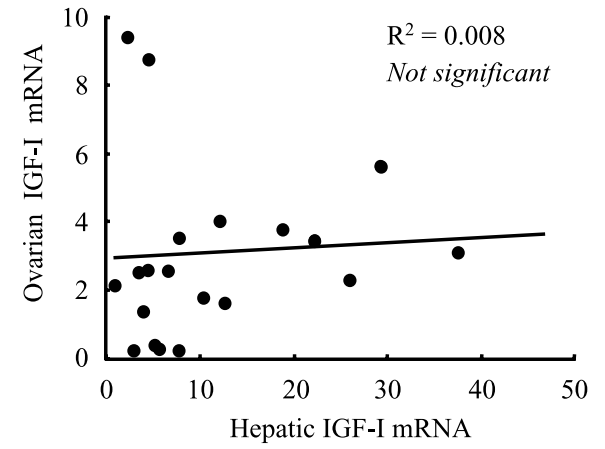

Figure 6 Correlation analysis between (A) hepatic GH-R mRNA and hepatic IGF-I mRNA, (B) between ovarian GH-R mRNA and ovarian IGF-I mRNA, (C) between hepatic GH-R mRNA and ovarian GH-R mRNA, and (D) between hepatic IGF-I mRNA and ovarian IGF-I mRNA at different stages of ovarian development. Data are expressed as $\times 10^{5}$ copies/ $\mu \mathrm{g}$ RNA.

byproteolytic cleavage of the GH-R (Sotiropoulos et al.1993). In teleosts, a short form of GH-R, which may encode a membrane-anchored truncated receptor, was cloned in the turbot (Calduch-Giner et al. 2001). On the other hand, the goldfish produces multiple forms of GHBP in the circulation (Zhang \& Marchant 1999), whereas a single transcript of GH-R was reported (Lee et al. 2001). To our knowledge, there seems to be no report on GHBP in the tilapia. The single transcript of the GH-R gene in the tilapia may indicate that GHBP could be produced by proteolytic cleavage of the GH-R.

In situ hybridization in the tilapia ovary revealed intense signals in the cytoplasm and nucleus of small oocytes at the perinucleolus stage and yolk vesicle stage, implying an important role of $\mathrm{GH}$ in the early stages of oocyte growth and development. This is supported by the findings that the GH-R/GHBP knockout mouse exhibits a reduced number of follicles (Bachelot et al. 2002), and that exogenous GH significantly increased the number of small follicles in the cow (Gong et al. 1991). We also found GH-R transcripts in the granulosa and theca cells surrounding vitellogenic oocytes, which is in agreement with other reports in mammals (Lobie et al. 1990, Carlsson et al.
1993, Sharara \& Nieman 1994, Kölle et al. 1998, Zhao et al. 2002). These results further strengthen the direct role of $\mathrm{GH}$ on follicular growth and cell differentiation of granulosa cells (Jia et al. 1986, Yoshimura et al. 1994), and possibly on steroidogenesis (Singh et al. 1988, Mason et al. 1990, Van der Kraak et al. 1990, Singh \& Thomas 1993). Interestingly, strong signals were detected in the somatic cells surrounding the follicles of vitellogenic oocytes. It has been shown that distinct amounts of GH-R mRNA and protein were observed in the cumulus cells of the bovine ovary during all stages of follicular development (Kölle et al. 1998) and that GH accelerates oocyte maturation depending on the cumulus cells synthesizing GH-R (Izadyar et al. 1997).

To further analyze the GH-R gene expression profile during oogenesis, we have quantified the mRNA levels of GH-R and IGF-I in the liver and ovary at various stages of ovarian development. In the liver, there was no significant change in GH-R or IGF-I mRNA throughout oogenesis. Hepatic GH-R mRNA was positively correlated with hepatic IGF-I mRNA, but not with ovarian GH-R or IGF-I mRNA. It should be noted that we did not find a significant change in plasma IGF-I during ovarian 
development. We have previously reported the positive correlation between plasma levels of IGF-I or liver IGF-I mRNA and somatic growth in the tilapia (Kajimura et al. 2001). Therefore, liver-derived IGF-I (i.e. circulating IGF-I) may not be a main contributor to ovarian development. To support our data, no significant change in GH-specific binding was reported during oogenesis in rainbow trout (Gomez et al. 1999). On the other hand, significantly higher levels of GH-R and IGF-I mRNA were found in the immature oocytes in agreement with our in situ hybridization study. A radioreceptor assay in rainbow trout indicated that the concentration of the GH-binding sites was highest during the early phases of follicular development (Gomez et al. 1999). We failed to find any significant changes in GH-R or IGF-I mRNA levels in the whole ovary. Since ovarian development in the tilapia is asynchronous and oocytes of different developmental stages are simultaneously found in the matured ovary, mRNA levels of GH-R or IGF-I in the whole ovary may not reflect the physiological status of each oocyte. In fact, we found relatively high error rates for mRNA levels in the whole ovary, which might repudiate what appeared to be potentially valid biological differences. Perrot et al. (2000) reported that high levels of IGF-I mRNA were found in the immature gonad; these were decreased along with gonadal development in the hermaphroditic gilthead seabream. Furthermore, IGF-I receptor was detected in the membrane of previtellogenic oocytes of this species. According to Yoshimura et al. (1994), an increase in follicle diameter by GH is correlated with intraovarian IGF-I contents in in vitro perfused rabbit ovaries, suggesting that the stimulatory effects of $\mathrm{GH}$ on follicular growth are mediated by ovarian IGF-I. These results indicate that paracrine/autocrine actions of the GH/IGF-I axis play an important role in the development or maintenance of the ovary in the early phases. In addition, IGF-I has also been known to regulate oocyte maturation and ovarian steroidogenesis in teleosts. Weber \& Sullivan $(2000,2001)$ reported that IGF-I induced oocyte germinal vesicle breakdown (GVBD) in the striped bass (Morone saxatilis) in association with phosphatidylinositol 3-kinase activity. However, the source of IGF-I (i.e. circulating IGF-I or intraovarian IGF-I) that induces GVBD is not known.

The different gene expression profiles of GH-R and IGF-I in the liver and in the ovary suggest different regulatory mechanisms of GH-R and IGF-I gene expression in these tissues, possibly by using alternate promoters. In some mammalian species, such as rat and bovine, a splicing variant containing exon 1 (1B) is expressed in hepatic and extrahepatic tissues including the ovary, whereas another variant (1A) is mainly expressed in the liver (Heap et al. 1996). According to Baumbach \& Bingham (1995), these 1A and 1B variants are differentially regulated by $\mathrm{GH}$ and sex steroids in the rat. The tissue-specific regulatory mechanism of
GH-R gene expression may account for the paracrine or autocine actions of GH/IGF-I in the ovary independent of hepatic-derived IGF-I.

\section{Acknowledgements}

We are indebted to Dr K Okubo, National Institute of Basic Biology, for his support and advice in mammalian cell culture, and to Ms S Hasegawa, Ocean Research Institute, University of Tokyo, for her support in fish maintenance.

\section{Funding}

This work was supported by grants from the US Department of Agriculture (no. 983506644), and the National Science Foundation (IBN 01-33714) to T H and E G G, and from the Japan Society for Promotion of Science (no. 11824) to S K.

\section{References}

Advis JP, White SS \& Ojeda SR 1981 Activation of growth hormone short loop negative feedback delays puberty in the female rat. Endocrinology 108 1343-1352.

Bachelot A, Monget P, Imbert-Bollore P, Coshigano K, Kopchick JJ, Kelly PA \& Binart N 2002 Growth hormone is required for ovarian follicular growth. Endocrinology 143 4104-4112.

Baumbach WR \& Bingham B 1995 One class of growth hormone $(\mathrm{GH})$ receptor and binding protein messenger ribonucleic acid in rat liver, GHR1, is sexually dimorphic and regulated by GH. Endocrinology 136 749-760.

Calduch-Giner J, Duval H, Chesnel F, Boeuf G, Perez-Sanchez J \& Boujard D 2001 Fish growth hormone receptor: molecular characterization of two membrane-anchored forms. Endocrinology 142 3269-3273.

Carlsson B, Nilsson A, Isaksson OG \& Billig H 1993 Growth hormone-receptor messenger RNA in the rat ovary: regulation and localization. Molecular and Cellular Endocrinology 95 59-66.

Danilovich NA, Bartke A \& Winters TA 2000 Ovarian follicle apoptosis in bovine growth hormone transgenic mice. Biology of Reproduction 62 103-107.

Frank SJ, Gilliland G, Kraft AS \& Arnold CS 1994 Interaction of the growth hormone receptor cytoplasmic domain with the JAK2 tyrosine kinase. Endocrinology 135 2228-2239.

Gomez JM, Mourot B, Fostier A \& Le Gac F 1999 Growth hormone receptors in ovary and liver during gametogenesis in female rainbow trout (Oncorhynchus mykiss). Journal of Reproduction and Fertility 115 275-285.

Gong JG, Bramley T \& Webb R 1991 The effect of recombinant bovine somatotropin on ovarian function in heifers: follicular populations and peripheral hormones. Biology of Reproduction $\mathbf{4 5}$ 941-949.

Govers R, ten Broeke T, van Kerkhof P, Schwartz AL \& Strous GJ 1999 Identification of a novel ubiquitin conjugation motif, required for ligand-induced internalization of the growth hormone receptor. EMBO Journal 18 28-36.

Heap D, Collier RJ, Boyd CK \& Lucy MC 1996 Expression of alternate growth hormone receptor messenger RNA in ovary and uterus of cattle. Domestic Animal Endocrinology 13 421-430. 
Homburg R 1996 Growth hormone and fertility - clinical studies. Hormone Research 45 81-85.

Hull KL \& Harvey S 2001 Growth hormone: roles in male reproduction. Journal of Endocrinology 168 1-23.

Izadyar F, Van Tol HT, Colenbrander B \& Bevers MM 1997 Stimulatory effect of growth hormone on in vitro maturation of bovine oocytes is exerted through cumulus cells and not mediated by IGF-I. Molecular Reproduction and Development 47 175-180.

Jia XC, Kalmijn J \& Hsueh AJ 1986 Growth hormone enhances follicle-stimulating hormone-induced differentiation of cultured rat granulosa cells. Endocrinology 118 1401-1409.

Kajimura S, Uchida K, Yada T, Riley LG, Byatt JC, Collier RJ, Aida K, Hirano T \& Grau EG 2001 Stimulation of insulin-like growth factor-I production by recombinant bovine growth hormone in the euryhaline tilapia, Oreochromis mossambicus. Fish Physiology and Biochemistry 25 221-230.

Kölle S, Sinowatz F, Boie G \& Lincoln D 1998 Developmental changes in the expression of the growth hormone receptor messenger ribonucleic acid and protein in the bovine ovary. Biology of Reproduction 59 836-842.

Laron Z \& Klinger B 1998 Effect of insulin-like growth factor-I treatment on serum androgens and testicular and penile size in males with Laron syndrome (primary growth hormone resistance). European Journal of Endocrinology 138 176-180.

Lee LT, Nong G, Chan YH, Tse DL \& Cheng CH 2001 Molecular cloning of a teleost growth hormone receptor and its functional interaction with human growth hormone. Gene 270 121-129.

Lobie PE, Breipohl W, Aragon JG \& Waters MJ 1990 Cellular localization of the growth hormone receptor/binding protein in the male and female reproductive systems. Endocrinology 126 2214-2221.

Mason HD, Martikainen H, Beard RW, Anyaoku V \& Franks S 1990 Direct gonadotrophic effect of growth hormone on oestradiol production by human granulosa cells in vitro. Journal of Endocrinology 126 R1-4.

Perrot V, Moiseeva EB, Gozes Y, Chan SJ \& Funkenstein B 2000 Insulin-like growth factor receptors and their ligands in gonads of a hermaphroditic species, the gilthead seabream (Sparus aurata): expression and cellular localization. Biology of Reproduction $\mathbf{6 3}$ 229-241.

Ramaley JA \& Phares CK 1980 Delay of puberty onset in females due to suppression of growth hormone. Endocrinology 106 1989-1993.

Reinecke M, Schmid A, Ermatinger R \& Loffing-Cueni L 1997 Insulin-like growth factor I in the teleost Oreochromis mossambicus, the tilapia: gene sequence, tissue expression, and cellular localization. Endocrinology 138 3613-3619.

Sharara FI \& Nieman LK 1994 Identification and cellular localization of growth hormone receptor gene expression in the human ovary. Journal of Clinical Endocrinology and Metabolism 79 670-672.

Shepherd BS, Sakamoto T, Nishioka RS, Richman NH III, Mori I, Madsen SS, Chen TT, Hirano T, Bern HA \& Grau EG 1997 Somatotropic actions of the homologous growth hormone and prolactins in the euryhaline teleost, the tilapia, Oreochromis mossambicus. PNAS 94 2068-2072.

Singh H \& Thomas P 1993 Mechanism of stimulatory action of growth hormone on ovarian steroidogenesis in spotted seatrout, Cynoscion nebulosus. General and Comparative Endocrinology 89 341-353.

Singh H, Griffith RW, Takahashi A, Kawauchi H, Thomas P \& Stegeman JJ 1988 Regulation of gonadal steroidogenesis in Fundulus heteroclitus by recombinant salmon growth hormone and purified salmon prolactin. General and Comparative Endocrinology 72 144-153.

Smith CJ \& Haley SR 1988 Steroid profiles of the female tilapia, Oreochromis mossambicus, and correlation with oocyte growth and mouthbrooding behavior. General and Comparative Endocrinology 69 88-98.

Smith WC, Kuniyoshi J \& Talamantes F 1989 Mouse serum growth hormone $(\mathrm{GH})$ binding protein has $\mathrm{GH}$ receptor extracellular and substituted transmembrane domains. Molecular Endocrinology 3 984-990.

Sotiropoulos A, Goujon L, Simonin G, Kelly PA, Postel-Vinay MC \& Finidori J 1993 Evidence for generation of the growth hormone-binding protein through proteolysis of the growth hormone membrane receptor. Endocrinology 132 1863-1865.

Thompson JD, Higgins DG \& Gibson TJ 1994 Clustal W: improving the sensitivity of progressive multiple sequence alignment through sequence weighting, position specific gap penalties and weight matrix choice. Nucleic Acids Research 22 4673-4680.

Tse DL, Tse MC, Chan CB, Deng L, Zhang WM, Lin HR \& Cheng CH 2003 Seabream growth hormone receptor: molecular cloning and functional studies of the full-length cDNA, and tissue expression of two alternatively spliced forms. Biochimica et Biophysica Acta 1625 64-76.

Van der Kraak G, Rosenblum PM \& Peter RE 1990 Growth hormone-dependent potentiation of gonadotropin-stimulated steroid production by ovarian follicles of the goldfish. General and Comparative Endocrinology 79 233-239.

Weber GM \& Sullivan CV 2000 Effects of insulin-like growth factor-I on in vitro final oocyte maturation and ovarian steroidogenesis in striped bass, Morone saxatilis. Biology of Reproduction $\mathbf{6 3}$ 1049-1057.

Weber GM \& Sullivan CV 2001 In vitro hormone induction of final oocyte maturation in striped bass (Morone saxatilis) follicles is inhibited by blockers of phosphatidylinositol 3-kinase activity. Comparative Biochemistry and Physiology B 129 467-473.

Yoshimura Y, Iwashita M, Karube M, Oda T, Akiba M, Shiokawa S, Ando M, Yoshinaga A \& Nakamura Y 1994 Growth hormone stimulates follicular development by stimulating ovarian production of insulin-like growth factor-I. Endocrinology 135 887-894.

Zhang X, Lu X, Jing N \& Zhu S 2000 cDNA cloning and functional expression of growth hormone receptor from soft-shelled turtle (Pelodiscus sinensis japonicus). General and Comparative Endocrinology 119 265-275.

Zhang Y \& Marchant TA 1999 Identification of serum GH-binding proteins in the goldfish (Carassius auratus) and comparison with mammalian GH-binding proteins. Journal of Endocrinology 161 255-262.

Zhao J, Taverne MA, van der Weijden GC, Bevers MM \& van den Hurk R 2002 Immunohistochemical localisation of growth hormone (GH), GH receptor (GHR), insulin-like growth factor I (IGF-I) and type I IGF-I receptor, and gene expression of GH and GHR in rat pre-antral follicles. Zygote 10 85-94.

Received 20 September 2003

Accepted 19 December 2003

Made available online as an

Accepted Preprint 7 January 2004 